NATIONAL LABORATORY

MANAGED BY UT-BATTELLE

FOR THE DEPARTMENT OF ENERGY

\title{
Verification of the Effectiveness of X-ray Machine Collimation
}

December 2013

Prepared by

Tyler Guzzardo

Jake Livesay

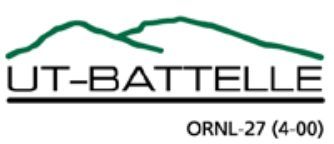




\title{
DOCUMENT AVAILABILITY
}

Reports produced after January 1, 1996, are generally available free via US Department of Energy (DOE) SciTech Connect.

\section{Website http://www.osti.gov/scitech/}

Reports produced before January 1, 1996, may be purchased by members of the public from the following source:

\author{
National Technical Information Service \\ 5285 Port Royal Road \\ Springfield, VA 22161 \\ Telephone 703-605-6000 (1-800-553-6847) \\ TDD 703-487-4639 \\ Fax 703-605-6900 \\ E-mail info@ntis.gov \\ Website http://www.ntis.gov/support/ordernowabout.htm
}

Reports are available to DOE employees, DOE contractors, Energy Technology Data Exchange representatives, and International Nuclear Information System representatives from the following source:

Office of Scientific and Technical Information

PO Box 62

Oak Ridge, TN 37831

Telephone 865-576-8401

Fax 865-576-5728

E-mail reports@osti.gov

Website http://www.osti.gov/contact.html

This report was prepared as an account of work sponsored by an agency of the United States Government. Neither the United States Government nor any agency thereof, nor any of their employees, makes any warranty, express or implied, or assumes any legal liability or responsibility for the accuracy, completeness, or usefulness of any information, apparatus, product, or process disclosed, or represents that its use would not infringe privately owned rights. Reference herein to any specific commercial product, process, or service by trade name, trademark, manufacturer, or otherwise, does not necessarily constitute or imply its endorsement, recommendation, or favoring by the United States Government or any agency thereof. The views and opinions of authors expressed herein do not necessarily state or reflect those of the United States Government or any agency thereof. 
Nuclear Security and Isotope Technology Division

\title{
Verification of the Effectiveness of X-ray Machine Collimation
}

\author{
Tyler Guzzardo \\ Jake Livesay*
}

*Mason Livesay Scientific

Date Published: December 2013

\author{
Prepared by \\ OAK RIDGE NATIONAL LABORATORY \\ Oak Ridge, Tennessee 37831-6283 \\ managed by \\ UT-BATTELLE, LLC \\ for the \\ US DEPARTMENT OF ENERGY \\ under contract DE-AC05-00OR22725
}





\section{CONTENTS}

Page

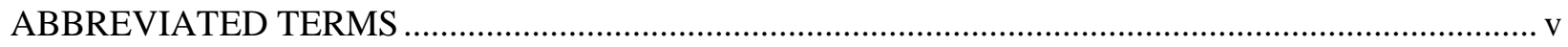

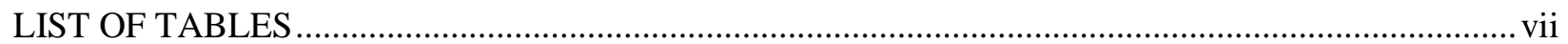

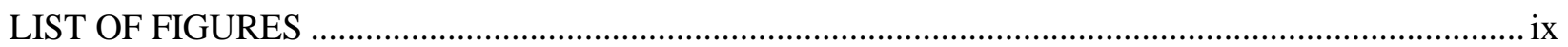

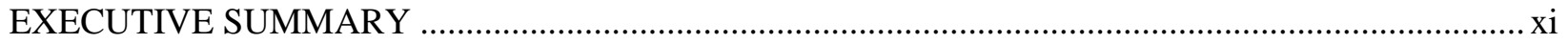

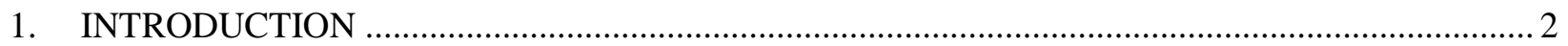

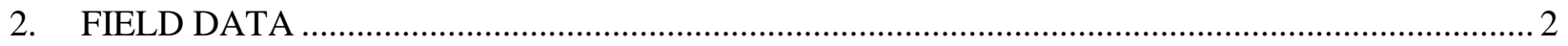

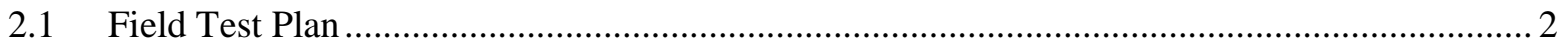

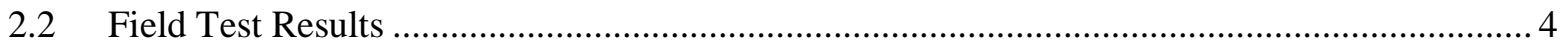

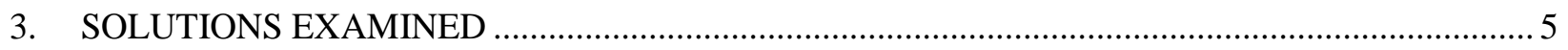

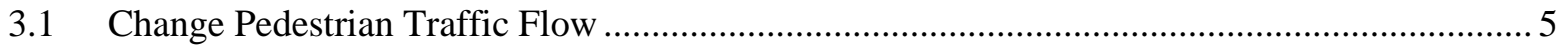

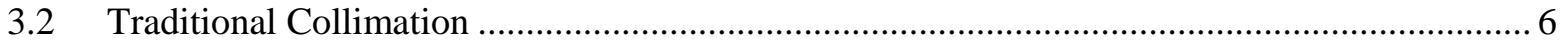

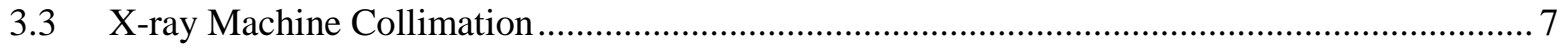

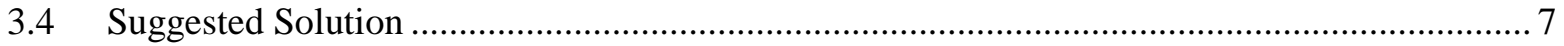

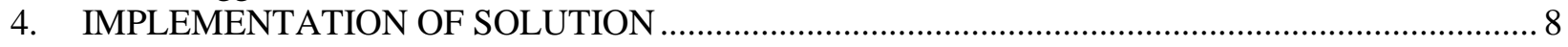

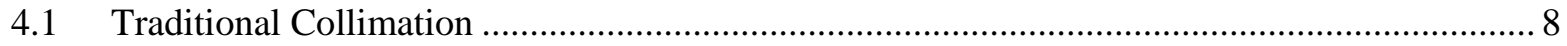

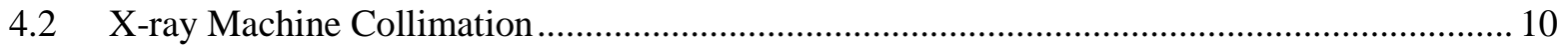

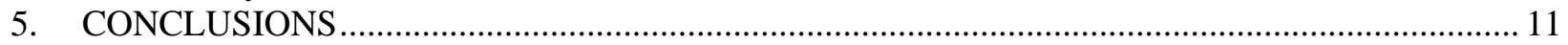

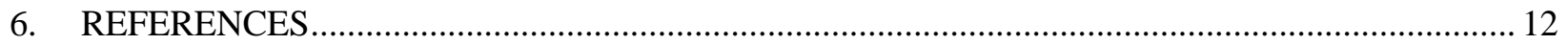

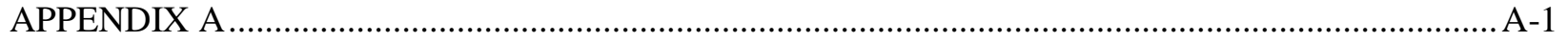





\section{ABBREVIATED TERMS}

$\begin{array}{ll}\mathrm{cm} & \text { centimeter } \\ \mathrm{keV} & \text { kilo electron volt } \\ \mathrm{kg} & \text { kilogram } \\ \mathrm{kV} & \text { kilovolt } \\ \mathrm{lb} & \text { pound } \\ \mathrm{m} & \text { meter } \\ \mathrm{NaI} & \text { sodium iodide } \\ \mathrm{ORNL} & \text { Oak Ridge National Laboratory } \\ \mathrm{RPM} & \text { radiation portal monitor } \\ \mathrm{ROI} & \text { region of interest } \\ \text { SLD } & \text { Second Line of Defense }\end{array}$





\section{LIST OF TABLES}

Table 1. Average count rate with no mobile lead shield (counts/second) ......................................... 4

Table 2. Average count rate with mobile lead shield (counts/second) .................................................. 4

Table 3. Average count rate in RPM 8 with lead curtains open (counts/second) .................................. 6

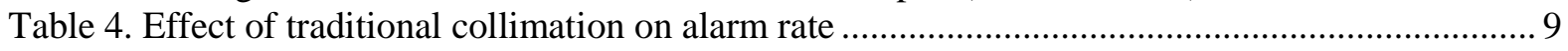

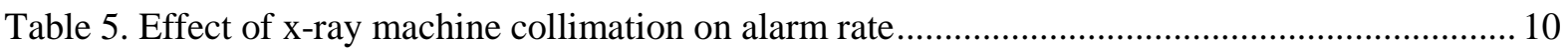

Table 6. Gamma attenuation in different shielding thicknesses.................................................. A-1 



\section{LIST OF FIGURES}

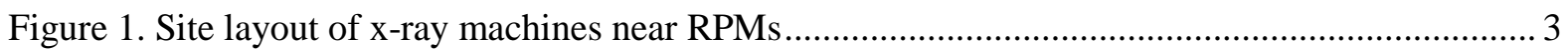

Figure 2. Mobile lead shielding unit positioned next to $\mathrm{x}$-ray machine ............................................... 3

Figure 3. Suggested pedestrian traffic route ................................................................................. 5

Figure 4. Gamma background plot for RPM 6 before and after collimator installation........................ 6

Figure 5. Simple model before (left) and after (right) installation of x-ray machine collimation.......... 7

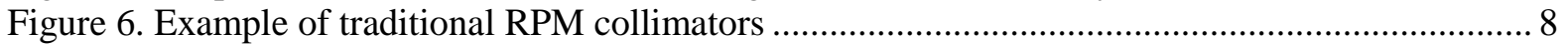

Figure 7. Effect of traditional collimation on background count rate ................................................ 9

Figure 8. X-ray machine before (left) and after (right) collimation was installed ............................... 10

Figure 9. Effect of x-ray machine collimation on background count rate.......................................... 11

Figure 10. Example $\mathrm{x}$-ray machine collimator technical drawing.................................................... A-1 



\section{EXECUTIVE SUMMARY}

The Oak Ridge National Laboratory (ORNL) was tasked by the United States National Nuclear Security Administration's Second Line of Defense (SLD) program with reducing the false alarm rate experienced by radiation portal monitors (RPM) installed near x-ray machines. Although the mechanism for interference between RPMs and x-ray machines is well understood, $\mathrm{x}$-ray machines are often installed too near RPMs due to a variety of facility constraints. The result is underutilized RPMs that are plagued by a high false alarm rate from x-rays that escape the x-ray machine and are detected by the RPM. In this work, the effectiveness of an x-ray machine collimation system designed at ORNL is validated through the analysis of field data collected before and after the installation. The significant reduction in false alarm rate due to the collimation system is explicitly shown, and examples of field installations are provided. Utilization of the results presented here allows RPM systems to operate effectively even when installed near x-ray machines. 


\section{INTRODUCTION}

Pedestrian radiation portal monitors (RPMs) installed at airports are often negatively influenced by nearby $\mathrm{x}$-ray machines. X-rays escape the x-ray machine and cause alarms when lead curtains used to attenuate the $\mathrm{x}$-rays are held open by luggage entering the machine. This increase in alarm rate can easily overwhelm airport staff and prevent secondary inspections from occurring regularly. Simple solutions to this issue are often not feasible due to restrictions placed on pedestrian flow, x-ray machine orientation, and RPM location. However, researchers at Oak Ridge National Laboratory have designed a collimation system that can be installed at the entrance of x-ray machines to stop x-rays at the source. Using collimation located at the source rather than at the detector can prevent unforeseen x-ray scattering from affecting the RPMs. If only collimation at the detector is installed, the angle at which x-rays are scattered out of the x-ray machine requires close examination to ensure none of the $x$-rays are within the field of view of the detector. Analysis of how the x-rays scatter is difficult, though, because $\mathrm{x}$-rays can scatter multiple times before being detected. Data recorded in the field show the benefit of installing x-ray machine collimators and that traditional collimation of the detector does not always attenuate all the escaped x-rays.

\section{FIELD DATA}

\subsection{FIELD TEST PLAN}

Field data were collected at a site that routinely experienced interference between RPMs ${ }^{*}$ and nearby $\mathrm{x}$-ray machines [2]. The perpendicular orientation of the $\mathrm{x}$-ray machines to the RPMs is shown in Figure 1 . This configuration allows $\mathrm{x}$-rays escaping the $\mathrm{x}$-ray machine to be easily detected by the RPMs. Although lead curtains existed over the opening of the $\mathrm{x}$-ray machines, $\mathrm{x}$-rays could escape through the opening created as luggage passed through the lead curtains. To quantify the interference caused by the nearby x-ray machines, measurements were recorded from each RPM to observe the background count rate as well as the increase in count rate while each $\mathrm{x}$-ray machine was operated. For these trials, three luggage baskets were placed in the lead curtains to simulate a piece of luggage holding the curtains open. This allowed the quantification of the baseline alarm rate experienced by the RPMs. This baseline was then compared to the increase in count rate observed when a mobile lead shielding unit was used to simulate one side of an x-ray machine collimator (Figure 2).

\footnotetext{
* TSA Systems PM700AGN pedestrian portal monitors [1]
} 

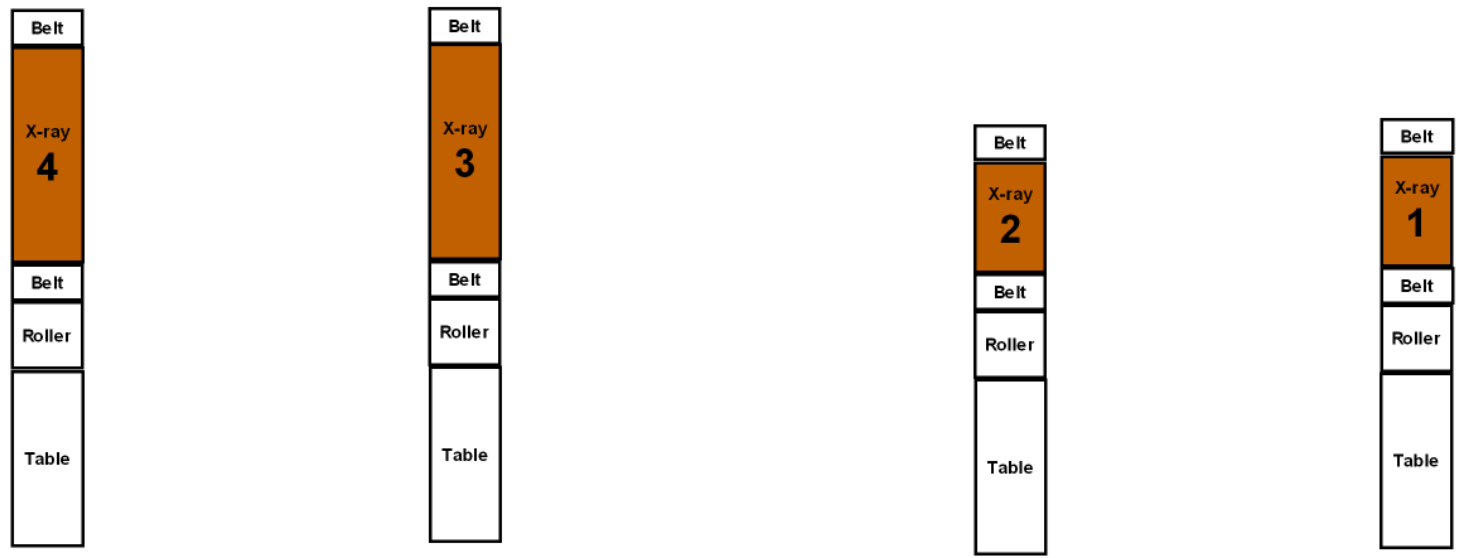

$$
\llbracket \leftarrow \text { RPM } 5 \rightarrow \square \square \leftarrow \text { RPM } 6 \rightarrow \square \square \leftarrow R P M ~ 7 \rightarrow \square \square \leftarrow R P M ~ 8 \rightarrow \square
$$

Figure 1. Site layout of x-ray machines near RPMs.

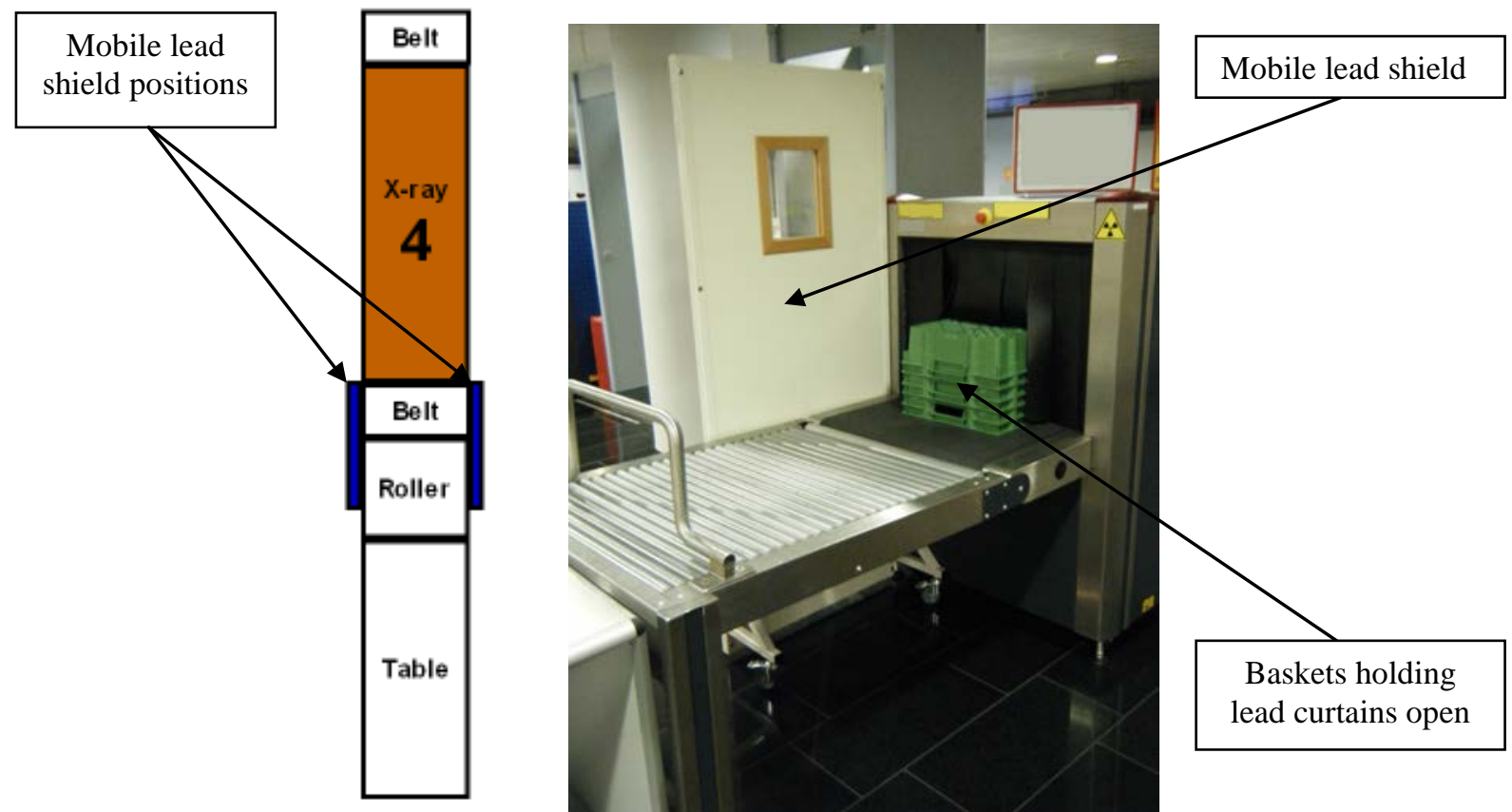

Figure 2. Mobile lead shielding unit positioned next to x-ray machine. 


\subsection{FIELD TEST RESULTS}

The influence of the x-ray machines on the RPMs was measured by recording five $1 \mathrm{~s}$ counts from each gamma detector in each RPM. Recording five measurements from each detector improved the reliability of the measurement while not being excessively time intensive. The resulting average count rates are presented in Tables 1 and 2. When the data in Table 2 were recorded, two mobile lead shielding units were used to simulate an $\mathrm{x}$-ray machine collimator and attenuate $\mathrm{x}$-rays escaping the $\mathrm{x}$-ray machine at an angle.

The highlighted cells in Table 1 and 2 represent sets of RPMs and x-ray machines that cause alarms. By comparing these tables, it is evident the alarm rate is significantly reduced by using the simulated $\mathrm{x}$-ray machine collimator. This is because many of the x-rays normally detected in the RPMs are emitted from the $\mathrm{x}$-ray machines at an angle. However, the single alarm in Table 2 suggests that enough $\mathrm{x}$-rays avoid the simulated collimator (by traveling straight out from the x-ray machine) to cause an alarm in an RPM positioned directly in front of the $\mathrm{x}$-ray machine. Overall, these data suggest installation of shielding in multiple orientations is required to eliminate the interference between the $\mathrm{x}$-ray machines and RPMs.

Table 1. Average count rate with no mobile lead shield (counts/second)

\begin{tabular}{|c|c|c|c|c|c|c|}
\hline & Background & Alarm threshold & X-ray 1 & X-ray 2 & X-ray 3 & X-ray 4 \\
\hline RPM 8 & 1322 & 1685 & 2042 & 1865 & 1360 & 1333 \\
\hline RPM 7 & 1307 & 1668 & 1376 & 2902 & 1537 & 1328 \\
\hline RPM 6 $^{a}$ & 652 & 908 & 663 & 649 & 709 & 695 \\
\hline RPM 5 & 1056 & 1381 & 1086 & 1099 & 1116 & 1648 \\
\hline
\end{tabular}

${ }^{a}$ Traditional collimators were present on RPM 6 when data were recorded.

Table 2. Average count rate with mobile lead shield (counts/second)

\begin{tabular}{|c|c|c|c|c|c|c|}
\hline & Background & Alarm threshold & X-ray 1 & X-ray 2 & X-ray 3 & X-ray 4 \\
\hline RPM 8 & 1322 & 1685 & 1388 & 1902 & 1385 & 1323 \\
\hline RPM 7 & 1307 & 1668 & 1326 & 1462 & 1460 & 1385 \\
\hline RPM 6 & 652 & 908 & 642 & 657 & 795 & 684 \\
\hline RPM 5 & 1056 & 1381 & 1070 & 1118 & 1131 & 1252 \\
\hline
\end{tabular}




\section{SOLUTIONS EXAMINED}

\subsection{CHANGE PEDESTRIAN TRAFFIC FLOW}

In many cases of x-ray machine interference, the simplest and most economical way to reduce the alarm rate is to route traffic through an RPM that is furthest from the operating x-ray machines. This is the case for the site layout shown in Figure 3 where pedestrians could be directed through RPM 8 and x-ray machines 3 and 4 . RPM 8 is far enough away from $x$-ray machines 3 and 4 that the generated $x$-rays will minimally affect the count rate in RPM 8. Table 3 shows the count rates recorded in RPM 8 while $x$-ray machines 3 and 4 were operating. For this trial, the lead curtains were removed from the $x$-ray machines to simulate a worst-case scenario. The increased count rate in RPM 8 during $x$-ray machine operation is significantly less than the alarm threshold. Since the increase in count rate is minimal, RPM 8 will not alarm as a result of operating x-ray machines 3 and 4 . If all the x-ray machines do not need to be operating at the same time, this is an attractive solution. However, airport personnel are often unwilling to make changes due to the difficulty of altering internal operating procedures. Furthermore, rerouting traffic is not a viable solution if the pedestrian traffic volume increases and all four x-ray machines need to be operated.

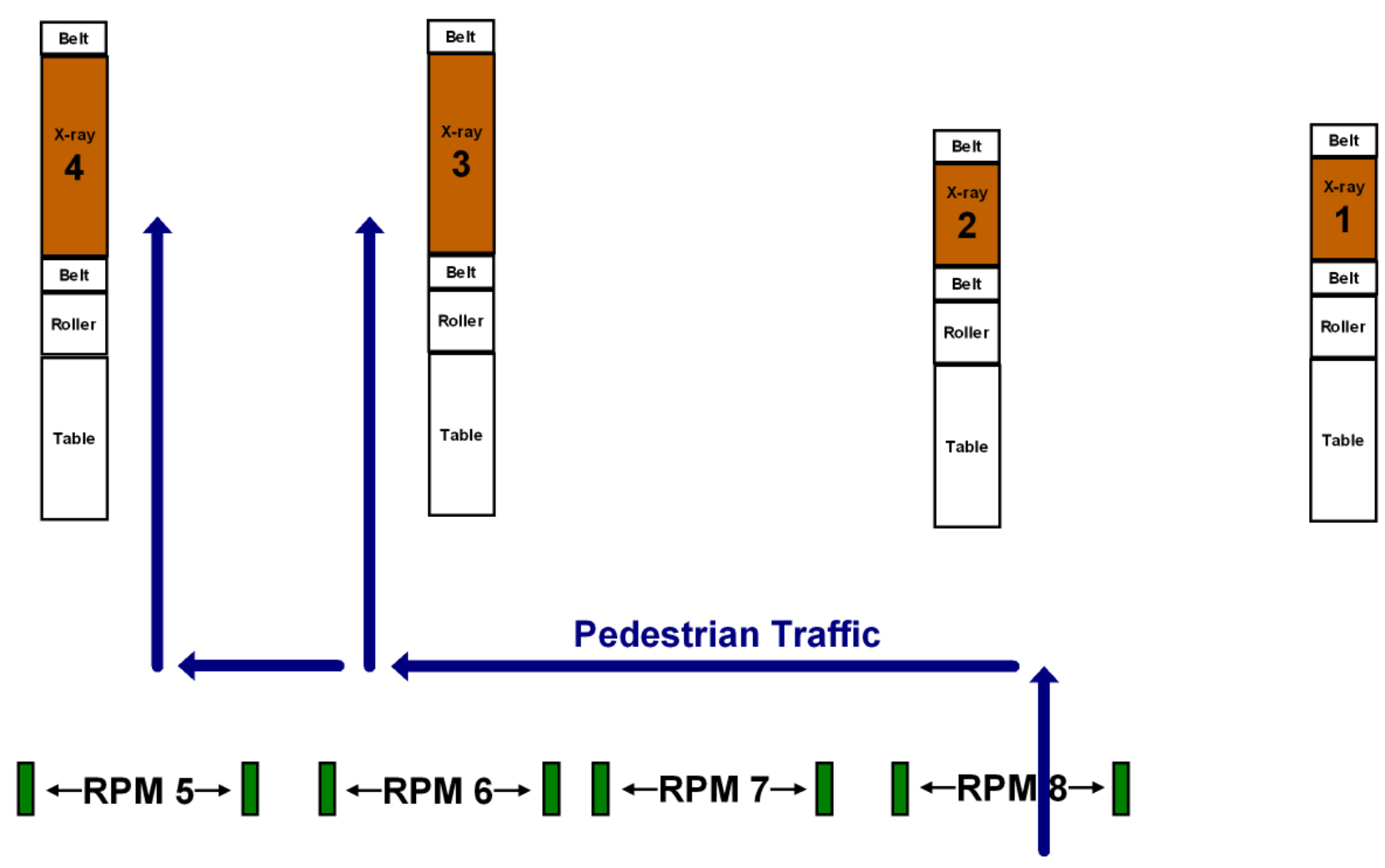

Figure 3. Suggested pedestrian traffic route. 
Table 3. Average count rate in RPM 8 with lead curtains open (counts/second)

\begin{tabular}{|c|c|c|c|c|c|}
\hline Detector \# & Background & Alarm threshold & X-ray 3 & X-ray 4 & X-rays 3 and 4 \\
\hline Detector 1 & 339 & 523 & 349 & 347 & 357 \\
\hline Detector 2 & 373 & 566 & 367 & 392 & 386 \\
\hline Detector 3 & 311 & 487 & 339 & 336 & 364 \\
\hline Detector 4 & 298 & 470 & 335 & 293 & 331 \\
\hline
\end{tabular}

\subsection{TRADITIONAL COLLIMATION}

An effective permanent solution is to install traditional collimators on every RPM. Collimators consist of lead shielding, approximately $1 \mathrm{~cm}$ in thickness, that narrows the detector view to approximately $45^{\circ}$ to either side of the normal of the detector face. X-ray machine interference is an excellent application for collimation because the x-ray machines are stationary and the emitted x-rays are entering the RPMs at an angle. The success of collimation at the field trial location is a proven concept; collimators were installed on RPM 6 in March 2009, and the alarm rate was reduced from an average of 48 alarms/day to 3 alarms/day. The average alarm rate the year before the collimators were installed was $2.195 \%$ (17,448 alarms out of 794,980 occupancies averaging 48 alarms/day). The average alarm rate the year after the collimators were installed was $0.121 \%$ (1,110 alarms out of 915,014 occupancies averaging 3 alarms/day).

Figure 4 shows the difference in the background signal in RPM 6 before and after the collimators were installed. The data on the left of the plot shows the background spikes from x-rays before the collimators were installed. The smooth data on the right shows the background after the collimators were installed. By comparing each side of the plot, it is evident the collimators sufficiently block the x-rays from entering the RPM.

Even though the collimators reduced the alarm rate for RPM 6, the same reduction in alarm rate for the other RPMs is not guaranteed. It is unknown which X-ray machines were in operation while pedestrians walked through RPM 6. If the airport rerouted traffic through the x-ray machine furthest from RPM 6, the reduction in alarm rate could be an aggregate of multiple actions. However, a significant reduction in alarm rate on all RPMs is expected.

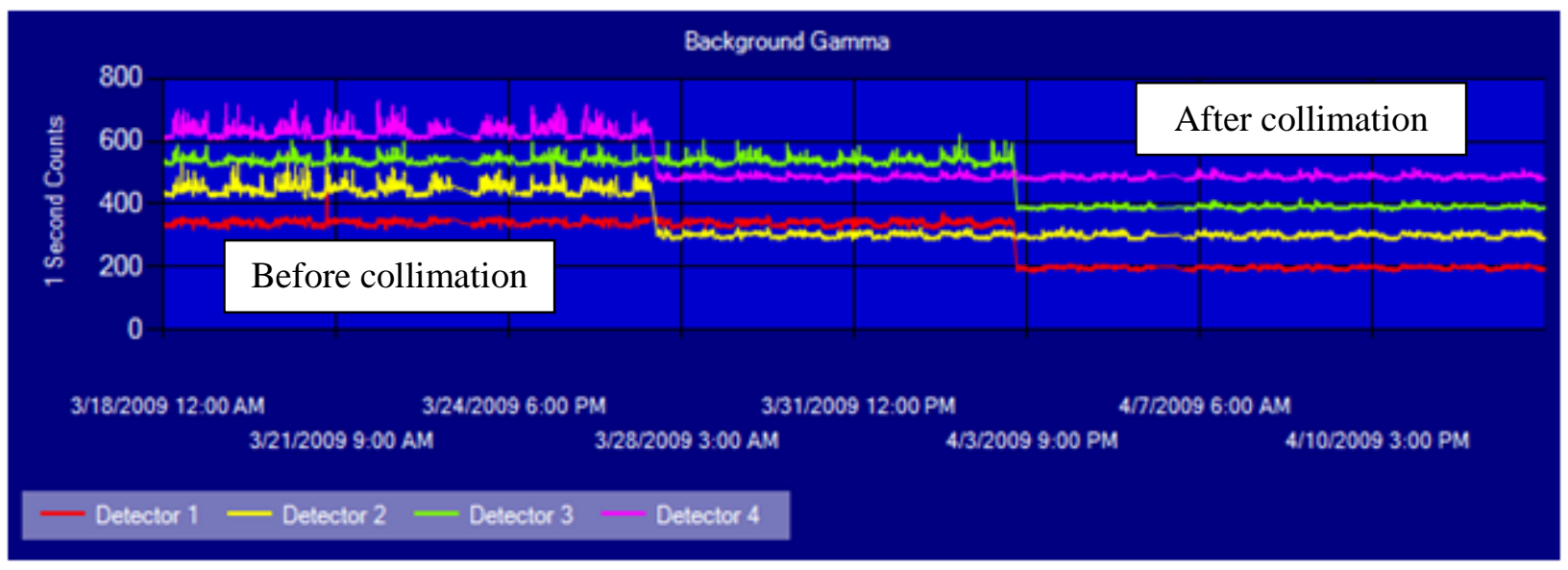

Figure 4. Gamma background plot for RPM 6 before and after collimator installation. 


\subsection{X-RAY MACHINE COLLIMATION}

The most comprehensive solution is to install additional shielding to the entrance of every $x$-ray machine in addition to collimating every RPM. Shielding in the form of x-ray machine collimators with an additional set of lead curtains addresses the problem at the source and prevents the majority of the x-rays from reaching the RPMs and causing alarms [3]. Since pedestrians will not be able to reach inside the collimator, an additional conveyor belt should be installed to move bags into the x-ray machine. Simplified drawings of an x-ray machine before and after installation are shown in Figure 5. The models are meant to simply describe the shape and dimensions of the x-ray machine collimator to be installed. A basic technical drawing that provided the foundation for the collimator that was installed is included in Figure 10 in the Appendix.
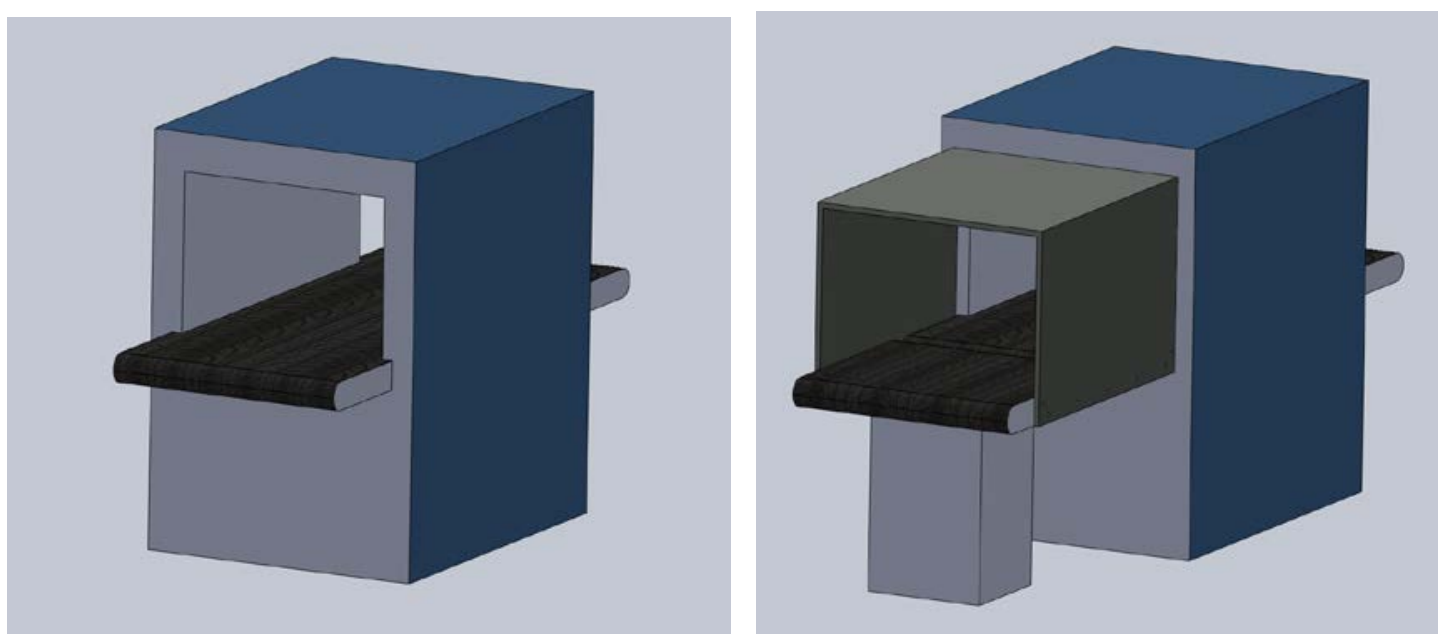

Figure 5. Simple model before (left) and after (right) installation of x-ray machine collimation.

\subsection{SUGGESTED SOLUTION}

The installation of both traditional RPM collimators and x-ray machine collimators was ultimately suggested to ensure the complete attenuation of x-rays escaping the x-ray machines. It was possible that traditional collimators alone could have reduced the alarm rate to a manageable level, so a phased approach to the solution was recommended. The traditional collimators were installed first so the reduction in alarm rate could be observed before installing x-ray machine collimators and further reducing the alarm rate. 


\section{IMPLEMENTATION OF SOLUTION}

\subsection{TRADITIONAL COLLIMATION}

Traditional lead collimators were installed on the RPMs to prevent some of the x-rays emitted from the $\mathrm{x}$-ray machines from being detected. Traditional collimators surround the polyvinyl toluene gamma detectors inside the RPM cabinet and extend from the back of the cabinet to the door (Figure 6). The goal of the collimators is to allow the RPM to detect only radiation originating between the RPM pillars. The commercial-off-the-shelf collimators had the potential to reduce the alarm rate to a manageable level, so they were installed before the additional x-ray machine collimators.

The traditional collimators did significantly reduce the alarm rate experienced by the RPMs (Table 4), but $\mathrm{x}$-rays were still detected by the RPM. Figure 7 shows how the collimators reduced the influence of the $\mathrm{x}$-rays on the RPM background count rate. Before the collimators were installed, large spikes were recorded in the background count rate when the x-ray machines were operated. After the collimators were installed, the spikes in the background plot decreased in magnitude due to attenuation of the $x$-rays by the lead. However, the traditional collimators did not completely prevent the x-rays from being detected.

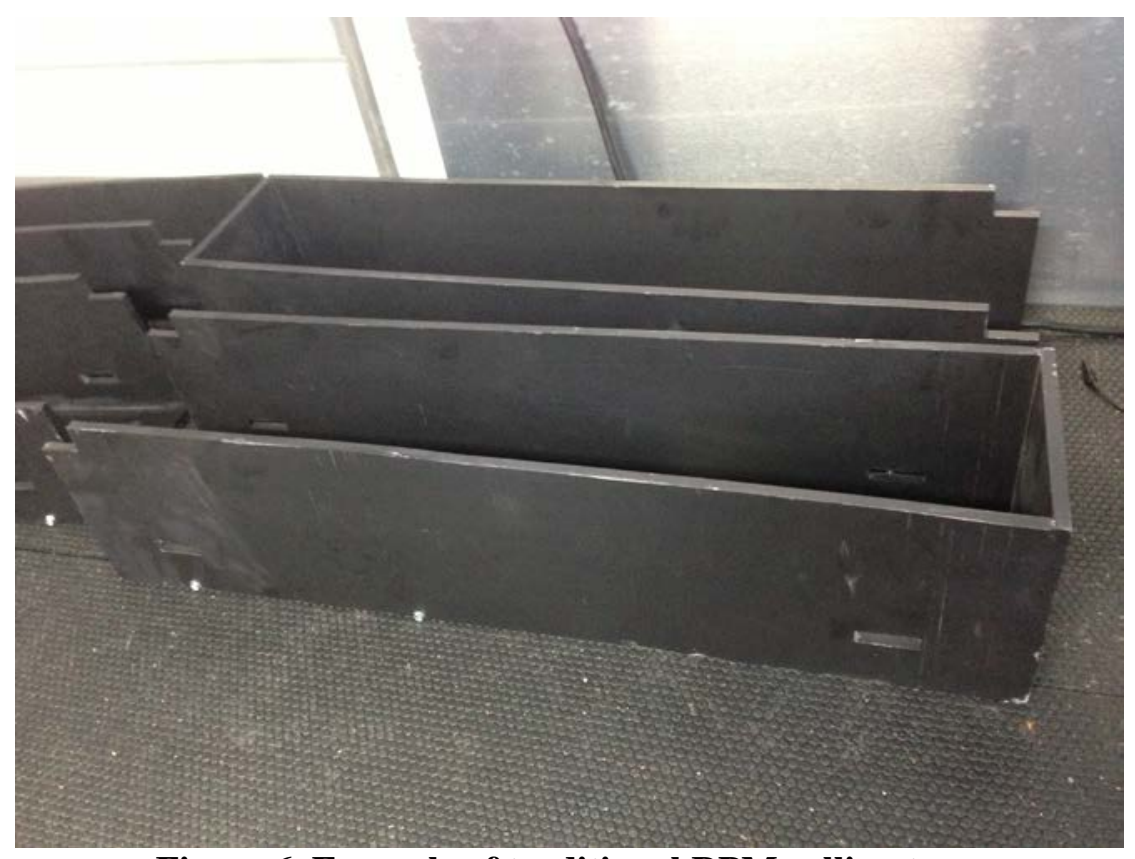

Figure 6. Example of traditional RPM collimators. 
Table 4. Effect of traditional collimation on alarm rate

\begin{tabular}{|c|c|c|}
\hline & $\begin{array}{c}\text { Average alarm rate before collimation } \\
(\%)\end{array}$ & $\begin{array}{c}\text { Average alarm rate after collimation } \\
(\%)\end{array}$ \\
\hline RPM 8 & 0.158 & 0.081 \\
\hline RPM 7 & 8.765 & 1.832 \\
\hline RPM 6 & 2.195 & 0.121 \\
\hline RPM 5 & 0.508 & 0.029 \\
\hline
\end{tabular}

X-rays detected before collimation causing large spikes in gamma background
X-rays detected after collimation causing smaller spikes in gamma background

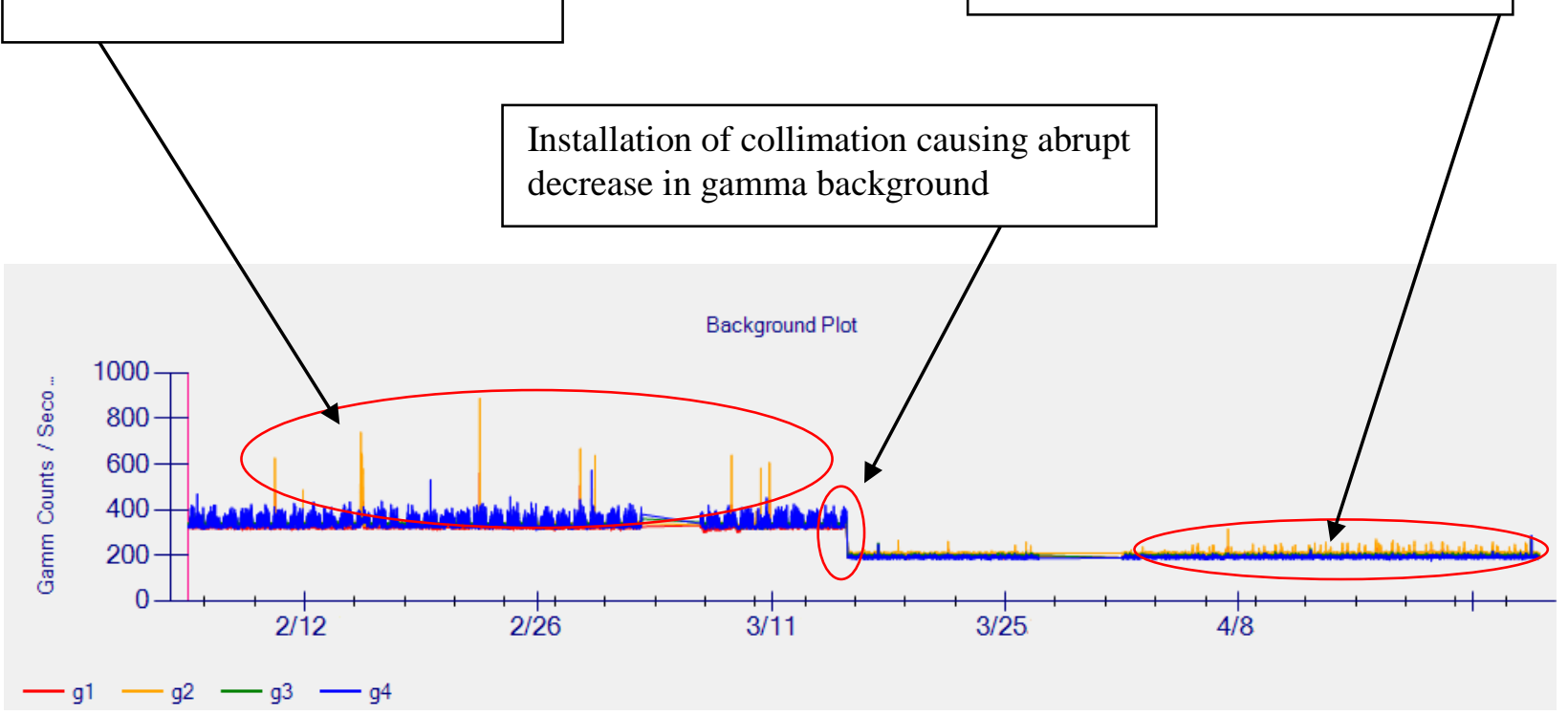

Figure 7. Effect of traditional collimation on background count rate. 


\subsection{X-RAY MACHINE COLLIMATION}

Since x-rays were still detected by the RPMs after traditional collimators were installed, $\mathrm{x}$-ray machine collimators were installed to further reduce the alarm rate (Figure 8). The x-ray machine collimators attenuated the x-rays at the source and prevented them from being detected by the RPM. Figure 9 graphically shows the effect of the x-ray machine collimation on the background count rate. After the $\mathrm{x}$-ray machine collimators were installed, $\mathrm{x}$-rays no longer caused spiking in the gamma background. This attenuation of the x-rays further reduced the alarm rate, as shown in Table 5 . Alarms caused by actual radioactive sources were included in the data presented in Table 5; therefore, the alarm rate recorded after the installation of the x-ray machine collimators is likely the lowest practically possible.
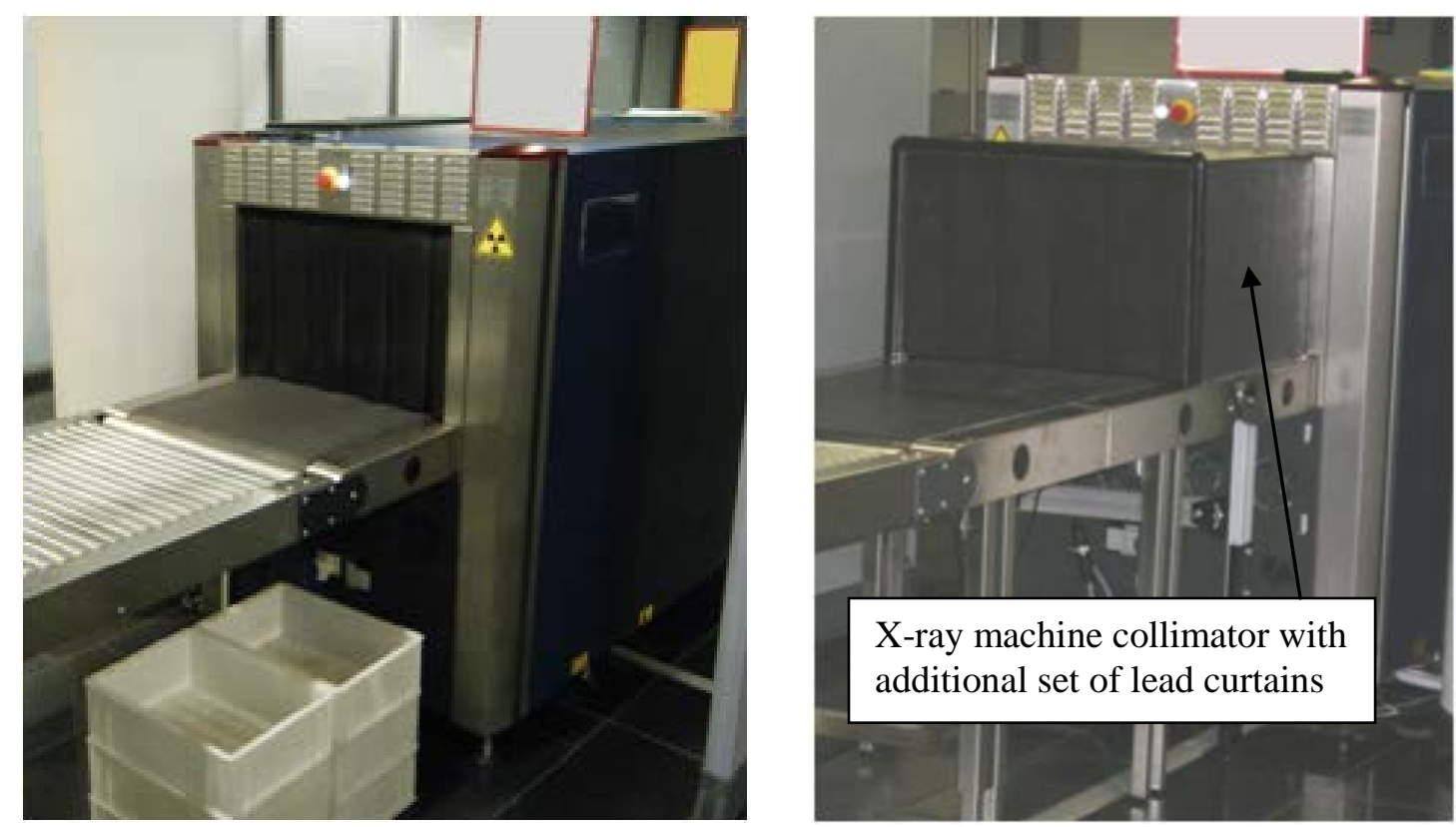

Figure 8. X-ray machine before (left) and after (right) collimation was installed.

Table 5. Effect of $x$-ray machine collimation on alarm rate

\begin{tabular}{|c|c|c|c|}
\hline & $\begin{array}{c}\text { Average alarm rate } \\
\text { before traditional } \\
\text { collimation (\%) }\end{array}$ & $\begin{array}{c}\text { Average alarm rate } \\
\text { after traditional } \\
\text { collimation (\%) }\end{array}$ & $\begin{array}{c}\text { Average alarm rate } \\
\text { after x-ray machine } \\
\text { collimation (\%) }\end{array}$ \\
\hline RPM 8 & 0.158 & 0.081 & 0.003 \\
\hline RPM 7 & 8.765 & 1.832 & 0.025 \\
\hline RPM 6 & 2.195 & 0.121 & 0.037 \\
\hline RPM 5 & 0.508 & 0.029 & 0.008 \\
\hline
\end{tabular}




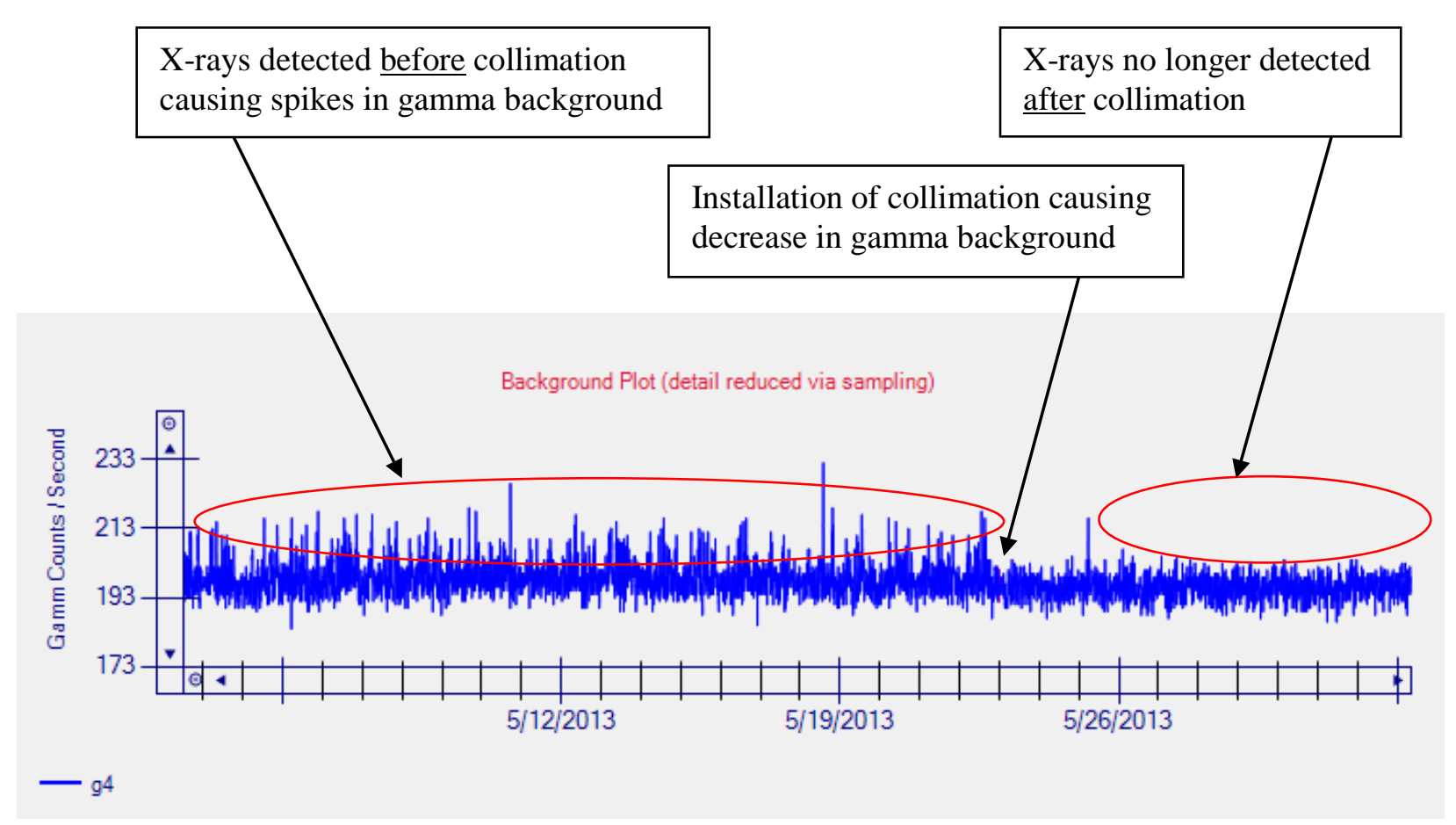

Figure 9. Effect of $x$-ray machine collimation on background count rate.

\section{CONCLUSIONS}

The combination of traditional RPM collimation and x-ray machine collimation virtually eliminated all alarms caused by x-rays escaping the nearby x-ray machines and maintained the desired sensitivity of the RPM. This work provides evidence that when internal operating procedures are inflexible and simple solutions are not feasible, collimation of the RPM and the x-ray machine can provide the attenuation necessary to reduce the high alarm rate caused by x-rays escaping nearby x-ray machines. Traditional collimation of only the RPM may not completely prevent x-rays from being detected by RPMs due to $\mathrm{x}$-rays scattering numerous times before being detected. However, x-ray machine collimators stop escaping $x$-rays at the source, so no calculation of scattering angles is required to determine if $x$-rays could still be within the field of view of the RPMs. Each RPM installation is unique with respect to the orientation of $\mathrm{x}$-ray machines and the viability of alternative solutions, but $\mathrm{x}$-ray machine collimation is an effective technique that should be considered for all future installations. 


\section{REFERENCES}

1. Pedestrian Monitor PM-700AGN Operations \& Service Manual, TSA Systems, Ltd., Doc 5038 Rev A, January 2011.

2. T. F. Guzzardo and R. J. Livesay, Second Line of Defense Alarm Rate Reduction Study, Oak Ridge National Laboratory, ORNL/GNSTD/SLD-2011-2-012, May 2011.

3. T. F. Guzzardo and R. J. Livesay, "Design of a New Collimation System to Prevent Interference between X-ray Machines and Radiation Portal Monitors,” Institute of Nuclear Materials Management, July 2012.

4. Smiths Detection, HI-SCAN 6040aTiX Heimann X-ray Inspection System Technical Specifications, May 2007.

5. Smiths Detection, HI-SCAN 7555si Heimann X-ray Inspection System Technical Specifications, May 2007. 


\section{APPENDIX A}

\section{A.1 TECHNICAL DRAWING}

A sample technical drawing of an x-ray machine collimator that would attach to the existing x-ray machine conveyor belt was created to provide a basis for a design (Figure 10). The thickness of the collimator is flexible because a lead composite material should be used that eliminates the chance of pedestrian exposure to lead. The lead equivalent thickness of the composite is required to be at least 0.2 $\mathrm{cm}$ to achieve the desired attenuation of x-rays (Table 6).
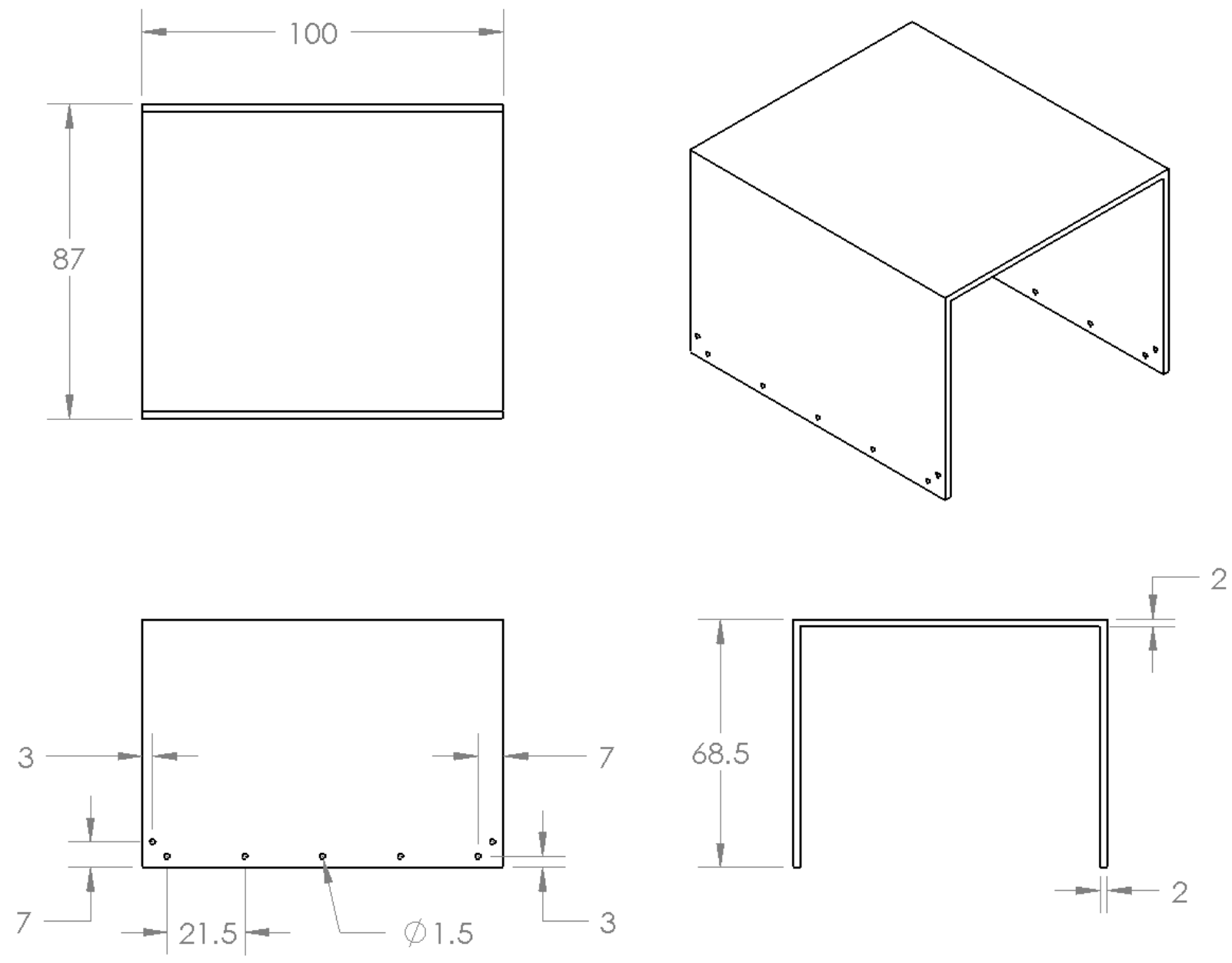

NOTE: ALL DIMENSIONS GIVEN IN CENTIMETERS

Figure 10. Sample x-ray machine collimator technical drawing. 
Table 6. Gamma attenuation in different shielding thicknesses

\begin{tabular}{|c|c|c|}
\hline Material & Thickness $(\mathrm{cm})$ & \% of gammas attenuated out of ROI \\
\hline Iron & 0.16 & 20.0 \\
\hline Iron & 0.32 & 35.8 \\
\hline Iron & 0.64 & 58.5 \\
\hline Iron & 1.27 & 82.0 \\
\hline Lead & 0.09 & 85.0 \\
\hline Lead & 0.32 & 93.6 \\
\hline Lead & 0.41 & 94.0 \\
\hline Lead & 0.64 & 94.4 \\
\hline Lead & 0.97 & 95.1 \\
\hline
\end{tabular}

\section{A.2 SHIELD THICKNESS JUSTIFICATION}

Numerous measurements were made to determine the required thickness of the shielding for the $x$-ray machine collimator. The most $\mathrm{x}$-ray attenuation possible is desired, but the weight of the collimator is the limiting factor to the shielding thickness. As the weight of the collimator increases, construction and installation of the collimator become more difficult.

An experiment was conducted to determine what thickness of shielding is required to scatter $\mathrm{x}$-rays out of the energy window used in the RPMs. Measurements were taken with a 2 in. $\times 2$ in. NaI detector with a cobalt-57 source positioned $6 \mathrm{~cm}$ in front of the detector. A cobalt- 57 source was used because its primary gamma ray is emitted at $122 \mathrm{keV}$, and gamma rays emitted at higher energies do not have significant branching ratios. $122 \mathrm{keV}$ was a reasonable energy to use because the $\mathrm{x}$-ray machines were operated at a maximum anode voltage of $160 \mathrm{kV}$ that produced a bremsstrahlung spectrum of x-rays with energies below $160 \mathrm{keV}[4,5]$. Sixty-second measurements were taken to record the number of counts in a region of interest (ROI) from $25 \mathrm{keV}$ to $140 \mathrm{keV}$. First, the number of gamma rays recorded in the ROI without shielding was determined. Then measurements were conducted with different shielding thicknesses, and the percent of gamma rays scattered out of the ROI was calculated (Table 6).

To attenuate approximately $85 \%$ of the $x$-rays, $0.09 \mathrm{~cm}$ of lead or $1.3 \mathrm{~cm}$ of iron is required. These thicknesses equate to an approximate collimator mass of $22 \mathrm{~kg}$ (49 lb) of lead or $225 \mathrm{~kg}$ (495 lb) of iron. The difference in mass is a consequence of the attenuating properties of the materials. The mass attenuation coefficients for lead and iron at $150 \mathrm{keV}$ are $2.014 \mathrm{~cm}^{2} / \mathrm{g}$ and $0.1964 \mathrm{~cm}^{2} / \mathrm{g}$, respectively. Overall, the required mass of iron makes iron shielding impractical.

Preventing $85 \%$ of the x-rays from being detected in the RPM will reduce the count rate below the original alarm threshold. However, if lowering the alarm threshold is a future goal, increasing the thickness of the shielding should be done now. It is recommended that a lead shield with a thickness of $0.2 \mathrm{~cm}$ should be installed. This thickness provides sufficient attenuation for a manageable collimator mass of approximately $50 \mathrm{~kg}(110 \mathrm{lb})$. 